\title{
The abundance and distribution of
} organic carbon in the seafloor sediments of the near offshore region surrounding Leizhou Peninsula, North Gulf of South China Sea

\author{
JIA XIA $^{12}$, YONG-QIANG HAN ${ }^{1}$
}

${ }^{1}$ College of Chemistry and Environmental Science, Guangdong Ocean University, Zhanjian 524088, P.R.China; xiaj@gdou.edu.cn

${ }^{2}$ Southern Marine Science and Engineering Guangdong Laboratory (Zhanjiang), Zhanjiang 524013, P.R.China

A total of 43 seafloor surface sediments collected from the surrounding offshore region of Leizhou Peninsula were analyzed in term of the total organic carbon content (TOC) and total nitrogen (TN) and sediment particle size. The results show that the organic carbon content in the seafloor surface sediments of the surrounding offshore region of Leizhou Peninsula is between 0 and $0.79 \%$, with an average of $0.26 \%$ which is significantly lower compared with other offshore regions of China. Only the sediments from the Liusha Bay area of the southwest of Leizhou Peninsula show a relatively higher TOC content. The total nitrogen content is in the range of $0.011 \%$ and $0.100 \%$ which is also low. While a clear positive correlation between TOC and TN suggests that nitrogen mainly exists in the form of organic compounds. The ratio of TOC/TN is between 5.1 and 14.3 , combined with the organic carbon isotope(-23.55\% $-20.83 \%$ ), implying a mixed input of organic matter from both terrestrial and marine authigenic sources. However, the terrestrial organic matter input seems to be significant in the northern offshore area of the western side of Leizhou Peninsula and the middle offshore area of the eastern side of Leizhou Peninsula. The correlations between the TOC and sediment particle size, $\mathrm{pH}$ \& Eh value of sediments indicates that the organic carbon content display a weak positive correlation with the content of clay and silt, and a loose negative correlation with the $\mathrm{pH}$ value, Eh value and content of sand in sediments. These correlations suggest that the TOC content and its distribution are comprehensively influenced by the source input of organic matter, the redox status of the seafloor sediments and the hydrodynamic condition of seawater. 